\title{
Seismic structure of Iceland from Rayleigh wave inversions and geodynamic implications
}

\author{
Aibing Li \\ Department of Geosciences, University of Houston, Houston, TX 77204 \\ Robert S. Detrick \\ Department of Geology and Geophysics, Woods Hole Oceanographic Institution, \\ Woods Hole, MA 02543
}

Earth and Planetary Science Letters 241 (2006) 901-912 


\begin{abstract}
We have constrained the shear-wave structure of crust and upper mantle beneath Iceland by analyzing fundamental mode Rayleigh waves recorded at the ICEMELT and HOTSPOT seismic stations in Iceland. The crust varies in thickness from 20 to $28 \mathrm{~km}$ in western and northern Iceland and from 26 to $34 \mathrm{~km}$ in eastern Iceland. The thickest crust of 34-40 km lies in central Iceland, roughly $100 \mathrm{~km}$ west to the current location of the Iceland hotspot. The crust at the hotspot is $\sim 32 \mathrm{~km}$ thick and is underlain by low shearwave velocities of $4.0-4.1 \mathrm{~km} / \mathrm{s}$ in the uppermost mantle, indicating that the Moho at the hotspot is probably a weak discontinuity. This low velocity anomaly beneath the hotspot could be associated with partial melting and hot temperature. The lithosphere in Iceland is confined above $60 \mathrm{~km}$ and a low velocity zone ( $\mathrm{LVZ}$ ) is imaged at depths of 60 to 120 $\mathrm{km}$. Shear wave velocity in the LVZ is up to $10 \%$ lower than a global reference model, indicating the influence of the Mid-Atlantic Ridge and the hotspot in Iceland. The lowest velocities in the LVZ are found beneath the rift zones, suggesting that plume material is channeled along the Mid-Atlantic Ridge. At depths of 100 to $200 \mathrm{~km}$, low velocity anomalies appear at the Tjornes fracture zone to the north of Iceland and beneath the western volcanic zone in southwestern Iceland. Interestingly, a relatively fast anomaly is imaged beneath the hotspot with its center at $135 \mathrm{~km}$ depth, which could be due to radial anisotropy associated with the strong upwelling within the plume stem or an Mgenriched mantle residual caused by the extensive extraction of melts.
\end{abstract}

Key words: Rayleigh wave, Iceland, crust, upper mantle, hotspot 


\section{Introduction}

Iceland is the product of the interaction between the Mid-Atlantic Ridge and the Iceland hotspot. The Iceland hotspot is believed to be currently located beneath the central and northwestern Vatnajokull icecap in southeastern Iceland (Fig. 1). The crust and upper mantle beneath Iceland have been well studied from seismic refraction, gravity, receiver function, and body wave tomography. Recent seismic refraction studies in Iceland include the SIST profile in southwest Iceland [1], the ICEMELT line across Iceland from the northwest to the southeast [2], the FIRE line in northeastern Iceland [3], and the AB96 line in northern Iceland [4]. The crustal thickness determined in these studies varies between $19 \mathrm{~km}$ to $40 \mathrm{~km}$ with the thickest crust located in central and southeastern Iceland. Maps of the 2-D variation in crustal thickness in Iceland obtained from receiver function analyses, gravity data, and Love waves all reveal relatively thin crust in western Iceland and thicker crust in central and eastern Iceland [5-7]. Allen et al. [6] reported the thickest crust of $46 \mathrm{~km}$ in southeastern Iceland near the hotspot while Foulger et al. [7] found the thickest crust in central Iceland, slightly west of the hotspot. Rayleigh wave phase velocity maps also show a low velocity anomaly in central Iceland at periods of 20 to $40 \mathrm{~s}$, which could be thick or slow crust [8].

Body wave tomography models [9-12] consistently show a low velocity conduit beneath Iceland that extends to at least $400 \mathrm{~km}$, which has been associated with the Iceland plume. These velocity models are more consistent below $200 \mathrm{~km}$ depth, but vary at shallower depths. For instance, Allen et al. [11] found a fast anomaly beneath the Iceland hotspot from the Moho to about $100 \mathrm{~km}$ depth. This anomaly does not exist in other published tomographic models of Iceland [9, 10, 12]. The shallow upper mantle 
beneath Iceland is not well imaged in these body wave studies [13]. One reason is that teleseismic ray paths are nearly vertical beneath Iceland and the number of crossing ray paths at shallow depths is very limited. Another reason is the effect of crustal structure. An incomplete correction for crustal thickness or velocity will have a larger effect on shallow upper mantle structure than on the structure at greater depths. Furthermore, body wave tomography models only resolve velocity perturbations, not the true velocity structure, which is more important in understanding how velocities vary with depth.

Surface waves propagate horizontally from a source to a receiver and provide important constraints on shear-wave structure in the crust and upper mantle. Analyzing Rayleigh wave data recorded at the ICEMELT and HOTSPOT stations, Li and Detrick [8] determined lateral variations of phase velocities and frequency-dependent azimuthal anisotropy in Iceland. In this study, we inverted Rayleigh wave phase velocities at periods from 20 to $125 \mathrm{~s}$ for shear-wave velocities beneath Iceland with high resolution to $200 \mathrm{~km}$ depth. Our Rayleigh wave models provide the absolute shear-wave velocities in the crust and upper mantle of Iceland at the first time and have important implications on geodynamic models of Iceland.

\section{Data and method}

We used Rayleigh wave phase and amplitude data from 80 distant earthquakes recorded at 15 ICEMELT and 33 HOTSPOT broadband seismic stations in Iceland [14,15] (Fig. 1). The ICEMELT and HOTSPOT experiments operated from 1995 to 1996 and from 1997 to 1998, respectively. A large number of stations and events used in this study yield dense crossing ray paths in Iceland and its vicinity (Fig. 2), which ensures 
high model resolution in these areas. Rayleigh waves are primarily sensitive to shearwave velocity and sensitive to P-wave velocity only at very shallow depths. The sensitivity of a Rayleigh wave to shear-wave structure depends on its period and the most sensitive depth is at $\sim 1 / 3$ of its wavelength. Fundamental mode Rayleigh waves at 13 frequencies were obtained by applying $10 \mathrm{mHz}$ wide, 4th order, double-pass Butterworth filters to the vertical component seismograms. The period of Rayleigh waves ranges from 20 to $125 \mathrm{~s}$, which sample the entire upper mantle with high resolution to the depth of $\sim 200 \mathrm{~km}$.

Our inversion method includes two steps. The first step inverts for phase velocities from Rayleigh wave phase and amplitude data. We applied a two-plane-wave inversion technique [16,17], which can account for non-planar energy due to scattering or multipathing in the incoming wave field. We parameterized the study area using 315 grid nodes with irregular node spacing. The nodes are dense in Iceland with a spacing of $0.75^{\circ}$ in longitude and $0.4^{\circ}$ in latitude, which is compatible to the average station spacing of $50 \mathrm{~km}$ in Iceland. We initially solved for average phase velocities in the study area assuming that phase velocities are equal at all grid nodes for a given frequency. Inversions for lateral variations of phase velocity were performed with minimum-length and smoothing criterion with the average phase velocities as starting values. A smoothing length of $80 \mathrm{~km}$ was used in the inversions.

The second step in the inversion method solves for shear-wave velocity structure from the phase velocities. We calculated the data kernels using the variational integral method by Thomson [18]. Details of the inversion method are described in the paper of Li et al. [17]. A 1-D velocity model of Iceland was constrained from the average phase 
velocities. This 1-D inversion started from the AK135 velocity model [19] with a modified crustal structure. We assumed a constant crustal thickness of $29 \mathrm{~km}$, an average value from the model of Allen et al. [6]. Starting crustal P and S velocities were also taken from the average values of the model by Allen et al. [6] and densities were based on the model of Staples et al. [3]. The crust is modeled as two layers, an upper, 10-kmthick layer with $\mathrm{Vp}=6.37 \mathrm{~km} / \mathrm{s}$ and $\mathrm{Vs}=3.47 \mathrm{~km} / \mathrm{s}$ and a lower, 19-km-thick layer with $\mathrm{Vp}=7.1 \mathrm{~km} / \mathrm{s}$ and $\mathrm{Vs}=3.79 \mathrm{~km} / \mathrm{s}$. Shear-wave velocities in 16 layers from the surface to $410 \mathrm{~km}$ are allowed to vary during the inversions. P wave velocities are scaled from the shear-wave velocities using the Vp/Vs ratios from the AK135 model. 3-D shear-wave models are constructed point by point from the 2-D phase velocity maps with the 1-D model of Iceland as an initial model. The crustal thickness is solved in the inversions for the 3-D structure by varying the thickness of the second layer in the crust and the top layer in the mantle. The total thickness of these two layers is a constant value of $43 \mathrm{~km}$.

\section{Results}

\subsection{Phase velocities}

Average phase velocities in Iceland vary from $3.59 \mathrm{~km} / \mathrm{s}$ at $20 \mathrm{~s}$ to $3.97 \mathrm{~km} / \mathrm{s}$ at 125 s (Fig. 3). These average velocities are well determined because only one model parameter is solved in the inversion for each period. The lateral variation of phase velocity is obtained through the 2-D inversions in which phase velocity is allowed to vary by grid node. Maps of phase velocity on a fine scale of $0.1^{\circ}$ by $0.1^{\circ}$ are generated from the grid values using a smoothing length of $80 \mathrm{~km}$. Fig. 4 shows phase velocity perturbations at six periods from $22 \mathrm{~s}$ to $83 \mathrm{~s}$. At short periods $(<40 \mathrm{~s})$, the slowest 
anomaly is imaged in central Iceland in a circular area, probably reflecting thick crust. The lowest phase velocities at $50 \mathrm{~s}$ form a narrow band in central Iceland and follow the trend of the rift zones. Relatively low velocities at longer periods concentrate in the western volcanic zone in southwestern Iceland and at the Tjornes fracture zone to the north of Iceland. Fast velocity anomalies are imaged in western and eastern Iceland in general. Interestingly, phase velocities at the hotspot in southeastern Iceland are also relatively high at longer periods. We presented more phase velocity measurements at two map points in southwestern and southeastern Iceland in Fig. 3, which clearly evidences the difference between the two dispersion curves.

The slow anomalies are up to 3\% at short periods and should be well resolved. At periods larger than $50 \mathrm{~s}$, most anomalies are within $\pm 2 \%$. To estimate the resolution of phase velocities, contours of twice standard deviations for phase velocity perturbations are plotted on the anomaly maps (Fig. 4). The standard deviation of phase velocity at map points are calculated from the model covariance matrixes in the phase velocity inversions. It can be seen that most anomalies are within the $1 \%$ contour even at longer periods, indicating that they are significantly resolvable. The lower the contour level is, the higher the resolution. It is not surprising that the highest resolution is in central Iceland given the dense distribution of stations and crossing ray paths there.

It has been well known that there is trade-off between lateral heterogeneity and azimuthal anisotropy. However, the effects of azimuthal anisotropy to phase velocity variations in Iceland should be averaged out in the inversions because the ray paths of surface waves are from a broad azimuthal range. In addition, the phase velocity maps from anisotropic inversions including azimuthal anisotropy by Li and Detrick [8] are 
remarkably similar to the maps in Fig. 4 from isotropic inversions. We therefore conclude that the effects of azimuthal anisotropy on our phase velocity models in Iceland are negligible.

\subsection{1-D shear-wave model}

The average shear-wave velocity beneath Iceland (Fig. 5) is significantly lower than the global model AK135 to at least $200 \mathrm{~km}$ depth. A strong low velocity zone is imaged from 60 to $120 \mathrm{~km}$ and the lowest velocity is $\sim 3.9 \mathrm{~km} / \mathrm{s}$. This model largely agrees with the shear-wave model of the Pacific Ocean at ages of 0-4 Ma [20]. It is also consistent with the shear-wave velocity beneath the Reykjanes Ridge [21] except that the LVZ beneath Iceland is much stronger. However, our model is clearly different from the shear-wave model of Iceland by Allen et al. [11], in which velocity increases almost linearly from the Moho to $200 \mathrm{~km}$ depth. Allen et al. [11] used Love waves with periods up to $67 \mathrm{~s}$, which have poor resolution below $100 \mathrm{~km}$. Radial anisotropy could also contribute to the differences between the Rayleigh and the Love wave models. The LVZ in our Rayleigh wave model would argue for strong horizontal flow if it is caused by anisotropy. The LVZ in our Iceland model is broader and deeper compared to that at the East Pacific Rise. If partial melting is responsible for this low velocity layer, it suggests that melting beneath Iceland starts at a greater depth $(\sim 120 \mathrm{~km})$ and more melts are produced, reflecting the influence of the Iceland hotspot.

The inversion for the 1-D shear-wave structure is an underdetermined inverse

problem because there are 16 model parameters and only 13 observations. The shearwave model is smoothed by applying a correlation coefficient of 0.4 between the adjacent layers. We used an a priori standard error of $0.1 \mathrm{~km} / \mathrm{s}$ for velocity model parameters so 
that the model was kept close to the initial model. Model resolution kernels (rows from the model resolution matrix) corresponding to three layers at depths of roughly 65,130 , and $200 \mathrm{~km}$ are plotted in Fig. 6. The resolution is not high enough to determine velocities in each individual layer, but good enough to resolve the average velocity in the targeted layer and its vicinity. For instance, the velocity at $65 \mathrm{~km}$ depth might be affected by velocity at depths of 50 to $100 \mathrm{~km}$, but not likely affected by velocity at depths below $120 \mathrm{~km}$. The decrease of resolution with depth is due to the lack of data at long periods (> $100 \mathrm{~s}$ ) and to the nature of surface waves that are most sensitive to the structure at the depths of $1 / 3$ of the wavelengths.

\subsection{Crustal structure}

Crustal thickness constrained from the inversion of Rayleigh wave data reveals strong variations across Iceland (Fig. 7a). Relatively thin crust of 20 to $28 \mathrm{~km}$ in thickness is imaged in western and northern Iceland. The crust is around $30 \mathrm{~km}$ thick in most of eastern Iceland and up to $34 \mathrm{~km}$ thick in the northeastern Iceland. These observations are broadly consistent with previous 2-D models of crustal thickness [5-7] even though our model is much smoother. Because the shortest wavelength of Rayleigh waves in our study is about $70 \mathrm{~km}$ and a smoothing length of $80 \mathrm{~km}$ is used in the phase velocity inversions, any sharp change of the Moho could be smoothed out in our model.

The thickest crust (34 to $40 \mathrm{~km}$ ) is observed in central Iceland, 100 km west to the current hotspot location. Beneath the hotspot in southeastern Iceland, we find $\sim 32 \mathrm{~km}$ thick crust, roughly 8-14 km thinner than in the models of Darbyshire et al. and Allen et al. $[5,6]$. Such a difference cannot be simply attributed to the different data and methods 
used in these studies. The main constraints on the Moho depth near the hotspot came from a few Moho reflections in the model of Darbyshire et al. [5]. These Moho reflections are not clear signals and might have been misidentified. In addition, they suggest that the Moho beneath the hotspot is a strong reflector while the lack of Sn phases [6] and the lack of clear P to S converted phases [22] from the Moho in southeast Iceland argue against this. The lack of Sn phase in southeastern Iceland could also contribute to the poor resolution to the Moho beneath the hotspot in the model of Allen et al. [6]. The discrepancy among different models suggests that the Moho beneath the Iceland hotspot is probably not well developed and therefore difficult to image accurately. This hypothesis is supported by the very low velocity imaged beneath the Moho at the hotspot in our Rayleigh wave model and by the weak $\mathrm{P}$ to $\mathrm{S}$ conversions and head waves.

Shear-wave velocity in the lower crust (Fig. 7b) roughly correlates with the surface tectonics. Velocity perturbations are calculated relative to the 1-D model of Iceland (Fig. 5). The variation of velocity in the lower crust is $\pm 1.5 \%$ across Iceland. The lowest velocities are confined to a narrow band beneath the eastern and northern volcanic zones where partial melt may exist. Velocities are generally low in the rift zones and relatively high in western and eastern Iceland. This low-velocity pattern is more like a mid-ocean ridge type structure rather than a plume type feature. We observed relatively high velocities under the western volcanic zone, which is in accord with the low attenuation measured in south Iceland $[23,24]$ and suggests that the lower crust here is relatively cold. This might be evidence for the waning of the western rift zone. The 
crust at shallow depths cannot be well resolved because of the lack of data at very short periods $(<20 s)$.

A thick crust can trade off with low velocities in the lower crust and in the uppermost mantle in Rayleigh wave inversions. To investigate this trade-off and its effect on the crustal thickness beneath the hotspot, we performed two tests. We took phase velocities at one map point $\left(-17^{\circ}, 64.5^{\circ}\right)$ at the hotspot and inverted the phase velocities for 1-D models by fixing crustal thickness at $31 \mathrm{~km}$ and $45 \mathrm{~km}$, respectively. The velocities in the crust and mantle were allowed to vary. The correlations between the observed and predicted phase velocities from the two models (Fig. 8) clearly show that the model with $31 \mathrm{~km}$ thick crust fits the Rayleigh wave data better. The model with a 45 $\mathrm{km}$ crust can predict phase velocities at intermediate and long periods, but the correlations are poor at the short periods ( $<=30 \mathrm{~s}$ ), which are more sensitive to crustal structure. Therefore, crust up to $45 \mathrm{~km}$ thick beneath the Iceland hotspot is not favored by Rayleigh wave data.

\subsection{Shear-wave structure in the upper mantle}

Shear-wave velocities in the upper mantle vary strongly across Iceland and with depth (Fig. 9 and 10). We calculated velocity perturbations relative to the 1-D average model of Iceland (Fig. 5), where the velocity in the LVZ is up to $10 \%$ lower than in the global model. Relatively fast anomalies are imaged in western and eastern Iceland at depths less than $100 \mathrm{~km}$ (Fig. 9a and 9b). This is not unexpected since these are the

oldest areas in Iceland. A low velocity anomaly (Fig. 9a) is imaged in central Iceland from the Moho to $\sim 80 \mathrm{~km}$ with the lowest value of $4.0 \mathrm{~km} / \mathrm{s}$ near the hotspot. At depths 
of 80 to $100 \mathrm{~km}$, the low velocity region develops to an elongated shape that is roughly parallel to the strike of the rift zones. However, the slowest area appears to the west of the northern rift zone, the location of the extinct ridge at $\sim 7$ Ma ago. This observation of offset between the low velocity anomaly and the ridge is also observed in a global tomography model [25], suggesting that the ridge migrates faster than the mantle beneath it.

The pattern of velocity anomalies at greater depths (Fig. 9c and 9d) is quite different from that at shallow depths. The slow anomalies below $100 \mathrm{~km}$ concentrate at the western volcanic zone in southwest Iceland and at the Tjornes fracture zone to the north of Iceland. This anomaly pattern is probably caused by the transform offsets which tend to block ridge parallel mantle flow [26]. We imaged a fast velocity anomaly centered at $~ 135 \mathrm{~km}$ depth beneath the hotspot in southeastern Iceland. This observation is a little surprising because the low velocity caused by high temperatures or the presence of melt is expected beneath the hotspot. While anomalously fast relative to the average velocity beneath Iceland, these velocities are about 4\% lower than model AK135 at these depths.

This fast anomaly at 100 to $200 \mathrm{~km}$ depth is well-resolved since it is located near the center of Iceland where the resolution in phase velocity models is high (Fig. 4). The resolution kernels in Fig. 6 demonstrate that an anomaly centered at the depth of $135 \mathrm{~km}$ with the lateral scale of $\sim 100 \mathrm{~km}$ is unlikely to be caused by the trade-off with a low velocity anomaly at the depth of $\sim 70 \mathrm{~km}$. This fast anomaly is likely the same structure imaged by Allen et al. [11] from body wave tomography although the fast anomaly in their model is slightly shallower. That other body wave tomography studies in Iceland 
$[9,10,12]$ do not image a fast anomaly beneath the hotspot is not surprising because the nearly vertical ray paths of teleseismic body waves limit their resolution at shallow depths. In addition, velocity anomalies are calculated relative to a global reference model in these body wave models $[9,10,12]$. The fast anomaly beneath the hotspot in our Rayleigh wave model would therefore appear as a negative anomaly and make it difficult to resolve.

The absolute velocities from the Rayleigh wave inversions provide a different perspective of the structure beneath Iceland than the velocity perturbations (Fig. 10). On the velocity profiles (Fig. 10a, c, and e), a low velocity zone is imaged at depths of 60 to $120 \mathrm{~km}$ beneath Iceland and the mantle lithosphere lid above the LVZ is confined above $60 \mathrm{~km}$. In contrast, on the velocity perturbation profiles (Fig. 10b, d, and f), there is no indication of a LVZ and the relative fast anomalies extend to $100 \mathrm{~km}$ depth and deeper. Thus, relative velocities alone cannot determine the vertical variation of the structure although they are useful for resolving the lateral heterogeneity in a region. The very low velocities (the second lowest contour) in the LVZ extend along the entire SW-NE profile consisting of the eastern and northern volcanic zones (Fig. 10e). On the E-W profile, the very low velocities exist only beneath the western and eastern volcanic zones (Fig. 10a). In contrast, the extent of these low velocities is more limited on the NW-SE profile (Fig. 10c), the direction that is perpendicular to the ridge. The pattern of these low velocities is in accord with the model of channeling of plume flow along the ridge.

Another important feature in our velocity model is a low velocity channel about $100 \mathrm{~km}$ wide in the mantle lithosphere beneath the hotspot. This channel, which links the crust and the LVZ, could be a conduit for transporting melt from the mantle to the crust. 
Shear-wave velocity in the channel is $4.0-4.1 \mathrm{~km} / \mathrm{s}$, and is probably associated with hot temperature and melt accumulation beneath the Moho. A slow uppermost mantle beneath the Iceland hotspot is also consistent with the weak Moho converted phases on receiver functions and the absence of Sn phases in southeastern Iceland [6, 22].

The fast anomaly beneath the hotspot is indicated by the concave-up velocity contours under the LVZ (Fig. 10a, c, and e). It is interesting to notice that all the velocity contours beneath the hotspot are concave up, including the contours in the LVZ. This image looks like a snapshot of a dynamic process in which the horizontal layers in the earth are distorted by a force pushing from below. However, the general increase in velocity with depth in the upper mantle is due to an increase in pressure. If the material is simply pushed upward, its velocity will eventually reduce by decompression and a fast anomaly should not be observed. Given the uncertainties in the upwelling rate of the Iceland plume and in the decompression rate of advected mantle rocks, we are not confident about that the dynamic upwelling is the cause of this fast anomaly.

\section{Discussion}

\subsection{Origin of low velocity anomalies}

Seismic velocity can be affected by many factors such as temperature, anisotropy, composition, and melt content. Very likely, two or more components make contributions to the observed velocity anomalies beneath Iceland. There are two low velocity anomalies on the W-E profile (Fig. 10b): one is at depths of 100 to $200 \mathrm{~km}$ beneath the western volcanic zone and the other appears at shallow depths $(<100 \mathrm{~km})$ right beneath the Iceland hotspot. The magnitude of the two anomalies is $\sim 2 \%$. One simple 
interpretation would be that both anomalies are caused by higher temperature associated with the hotspot. The mantle associated with these two anomalies would be roughly $220^{\circ} \mathrm{K}$ hotter than the ambient mantle assuming a $1.1 \%$ increase on shear-wave velocity for a $100^{\circ} \mathrm{K}$ increase in temperature [27]. This estimate of the excess temperature in the plume conduit is compatible with that from body wave tomography [9-12].

However, the story is probably not this simple. Partial melting must exist beneath Iceland and contribute to low velocities, especially the low velocity anomaly immediately beneath the Moho near the hotspot, where the shear velocity is as low as $\sim 3.9 \mathrm{~km} / \mathrm{s}$ in the LVZ, about $15 \%$ slower than in the AK135 reference model. Such a low velocity suggests the presence of partial melt although the actual melt fraction is difficult to estimate because it depends on how melt is distributed in the matrix. For example, the melt fraction can vary from $1 \%$ to $5 \%$ for the model of wet films and the model of melt pockets and tubes [28]. The observed slow mantle anomalies therefore must be resulted from both high temperature and partial melting.

\subsection{Origin of the fast anomaly}

The $2 \%$ fast anomaly centered at $\sim 135 \mathrm{~km}$ beneath the hotspot cannot be explained by temperature variations. Otherwise, this fast anomaly would indicate that the region at $100-200 \mathrm{~km}$ depths beneath the hotspot is about $440^{\circ} \mathrm{K}$ colder than that beneath the western rift zone at the same depth range. Such a cold anomaly is unable to remain stable beneath a hotspot where upwelling flow continuously brings hot mantle materials from below. Hence, cold temperature is not likely the cause of this high velocity 
anomaly and temperature variation alone cannot explain all the observed velocity anomalies.

Anisotropy may be responsible for the fast anomaly beneath the hotspot. Strong upwelling mantle flow is expected within the plume conduit as demonstrated in numerical models [29-31]. This flow tends to align olivine a-axes in a vertical direction, which results in a weak azimuthal anisotropy and a strong radial anisotropy with a vertical symmetry axis. Therefore, vertically polarized Rayleigh waves will see this radial anisotropy as a fast anomaly. The upwelling requires a less dense and hotter mantle column. If the center of the upwelling is about $200^{\circ} \mathrm{K}$ degree hotter, this temperature excess can lower the velocity by $\sim 2 \%$. Considering the temperature effect, the apparent $2 \%$ fast anomaly indicates a $4 \%$ increase in shear velocity due to anisotropy. The absolute 4\% radial anisotropy is compatible to that observed beneath the Reykjanes Ridge [21]. If anisotropy is the only source of the fast anomaly, it should disappear on Love wave images, which should be conducted in the future to test this hypothesis.

An alternative interpretation for the fast anomaly beneath the Iceland hotspot is that it reflects a compositional mantle residue after the extraction of melt from the mantle source associated with hotspot volcanism. This depleted, less dense layer beneath Iceland hotspot was proposed by Jordan [32] in 1979. Because melt generated in the plume conduit migrates upward, the residual mantle left behind becomes more depleted and Mg-rich, and will be associated with a higher velocity [32-34]. The fast anomaly we imaged is centered at 135 km depth, while the initial depth of melting beneath Iceland is estimated at $\sim 110 \mathrm{~km}$ depth from geochemistry data [35], which is adopted in geodynamical modeling [29-31]. However, the mantle beneath Iceland probably contains 
more water and eclogite [36-39], which will allow melting to start at greater depths. The viscosity in the depleted mantle residue gradually increases with time as more melt is extracted. This process should reduce the upwelling flow rate and the flow-induced radial anisotropy within the plume stem. Including a melting-induced layer of dehydration, Ito et al. [30] were able to predict along-axis crustal thickness, bathymetric and gravity variations in Iceland. The dehydrated layer in their model is placed above $\sim 110 \mathrm{~km}$, which is not consistent with the very low velocity we observed at the same depth range. It would be interesting to find out whether it is dynamically reasonable if a relatively viscous layer is placed at the depths of $100-200 \mathrm{~km}$ beneath the Iceland hotspot.

\subsection{Isostatic compensation at the Iceland hotspot}

Because the crustal thickness at the Iceland hotspot is roughly $10 \mathrm{~km}$ thinner in our model than that in some previous models $[5,6]$, would the density variations in the mantle provide enough support for the high topography at the hotspot? The density contrast across the Moho beneath the hotspot is $<0.1 \mathrm{~g} / \mathrm{cm}^{3}$ in the model of Darbyshire et al. [5], which is much smaller than the global average. Considering uncertainties, a density contrast of $0.2 \mathrm{~g} / \mathrm{cm}^{3}$ with $2.96 \mathrm{~g} / \mathrm{cm}^{3}$ in the crust and $3.16 \mathrm{~g} / \mathrm{cm}^{3}$ at the shallow mantle would be a conservative estimation. Using these numbers, the buoyancy of a 10 $\mathrm{km}$ crustal root is equivalent to a $100 \mathrm{~km}$ thick mantle column with $0.6 \%$ density reduction. This density reduction can be achieved by thermal expansion of a $200^{\circ} \mathrm{K}$ increase in temperature within the plume stem assuming a coefficient of thermal expansion $\alpha=3 \times 10^{-5} /{ }^{\circ} \mathrm{K}$ [32]. In addition, the depletion of iron in the mantle beneath 
the hotspot can lower the density as well. It is quite controversial in scaling shear velocity anomalies to Mg\# variations. Here we simply use the results given by Lee [40] with $\delta \ln v_{s} / \delta \mathrm{Mg} \#=0.0143$ and $\delta \ln \rho / \delta \mathrm{Mg} \#=-0.0144$. Assuming uniform temperature, the fast anomaly of $2 \%$ beneath the hotspot, if purely caused by depletion, corresponds to an increase of $1 \mathrm{in} \mathrm{Mg} \#$ and $1.4 \%$ reduction in density. If a $200^{\circ} \mathrm{K}$ temperature increase in the plume stem is included, the fast anomaly due to depletion is about $4 \%$ and the changes in Mg\# and density could be doubled. Either thermal expansion or iron depletion can produce sufficient buoyancy to explain the elevation of the hotspot region despite the $\sim 10 \mathrm{~km}$ thinner crust inferred in this study.

\subsection{Channeling of flow along ridge axes}

It is still debatable that whether the plume material beneath Iceland is channeled along ridge axes or spreads in a radial fashion from the plume center. Numerical models of both types are able to predict the crustal variations in Iceland and the V-shaped gravity anomalies at the Reykjanes Ridge [29-33, 40]. Since olivine a-axes tend to align in mantle flow directions, seismic anisotropy can be used to constrain mantle flows. Shearwave splitting measurements at the ICEMELT and HOTSPOT stations $[8,41]$ reveal NNE-SSW fast direction in western Iceland, NNW-SSE fast direction in eastern Iceland, and weak but varied anisotropy in the rift zones. The pattern of azimuthal anisotropy from shear-wave splitting does not agree with any flow models related to the Iceland

plume. Azimuthal anisotropy from Rayleigh waves [8] imaged a ridge-parallel fast direction in the rift zones and supported the channeling-flow model. However, the radial flow model cannot be completely ruled out because the Iceland plume is on the ridge and 
the rift axis is one radial direction across the hotspot. Isotropic velocities may help to constrain geodynamic models assuming that plume material is hot and slow. A recent study of regional surface wave tomography in the North Atlantic shows that low velocities are located beneath the Mid-Atlantic Ridge including Iceland and the fast direction of anisotropy are close to NS in Iceland [42], consistent with anisotropic Rayleigh wave phase velocities observed by Li and Detrick [8]. In our Rayleigh wave models, the very low velocities at depths of $70-120 \mathrm{~km}$ extend along the Icelandic rift zones, suggesting that plume material is channeled along the ridge axes at the base of the lithosphere beneath Iceland and arguing for the channeling-flow model.

\section{Conclusions}

The crustal thickness in Iceland varies from 20 to $40 \mathrm{~km}$ with the thickest crust imaged in central Iceland. The crust at the hotspot is about $30 \mathrm{~km}$ thick and is underlain by a low velocity anomaly in the uppermost mantle, indicating that the seismic Moho beneath the hotspot is probably not well developed. The low velocity anomaly forms a lithospheric conduit beneath the hotspot, which is probably associated with hot temperature and partial melting. We observe a low velocity zone at depths of 60 to 120 $\mathrm{km}$ beneath all of Iceland. The lowest velocities in the LVZ tend to extend along the rift zones, consistent with models of channeled plume flow along the ridge axes in Iceland. A fast anomaly at depths of 100 to $200 \mathrm{~km}$ is imaged beneath the hotspot. This anomaly may originate from radial anisotropy caused by upwelling flow in the plume stem and/or a depleted mantle residual associated with extensive melt extraction.

\section{Acknowledgement:}


We thank Richard Allen for providing us his crustal model in Iceland. Comments from Stuart Hall, Yang Shen, Richard Allen, and one anonymous reviewer are helpful for us to improve this paper. We benefited from discussions with Garrett Ito, Yaoling Niu, and Cin-Ty Lee. Thanks to IRIS DMC for making the data available. This work is supported by University of Houston, Woods Hole Oceanographic Institution, and NSF grant OCE-0117938. 


\section{References}

[1] I.T. Bjarnason, W. Menke, O.G. Flovenz, D. Caress, Tomographic image of the MidAtlantic plate boundary in southwest Iceland, J. Geophys. Res. 98 (1993) 6607-6622.

[2] F.A. Darbyshire, I.T. Bjarnason, R.S. White, O.G. Flovenz, Crustal structure above the Iceland mantle plume imaged by the ICEMELT refraction profile, Geophys. J. Int. 135, (1998) 1131-1149.

[3] R.K. Staples et al., Faroe-Ieland Ridge Experiment 1. Crustal structure of northeastern Iceland, J. Geophys. Res. 102 (1997) 7849-7866.

[4] W. Menke, M. West, B. Brandsdottir, D. Spark, Compressional and shear velocity structure of the lithosphere in northern Iceland, Bull. Seism. Soc. Am. 88 (1998) 1561-1571.

[5] F.A. Darbyshire, R.S. White, K.F. Priestley, Structure of the crust and uppermost mantle of Iceland from a combined seismic and gravity study, Earth Planet. Sci. Lett. 181 (2000) 409-428.

[6] R.M. Allen et al., Plume-driven plumbing and crustal formation in Iceland, J. Geophys. Res. 107 (2002) 10.1029/2001JB000584.

[7] G.R. Foulger, Z. Du, B.R. Julian, Icelandic-type crust, Geophys. J. Int. 155 (2003) 567-590.

[8] A. Li, R.S. Detrick, Azimuthal anisotropy and phase velocity beneath Iceland: implication for plume-ridge interaction, Earth Planet. Sci. Lett. 214 (2003) 153-165.

[9] C.J. Wolfe, I.T. Bjarnason, J.C. VanDecar, S.C. Solomon, Seismic structure of the Iceland mantle plume, Nature 385 (1997) 245-247. 
[10] G.R. Foulger et al., Seismic tomography shows that upwelling beneath Iceland is confined to the upper mantle, Geophys. J. Int. 146 (2001) 504-530.

[11] R.M. Allen et al., Imaging the mantle beneath Iceland using integrated seismological techniques, J. Geophys. Res. 107 (2002) 10.1029/2001JB000584.

[12] S.H. Hung, Y. Shen, L.Y. Chiao, Imaging seismic velocity structure beneath the Iceland hot spot: A finite frequency approach, J. Geophys. Res. 109 B08 (2004) doi: 10.1029/2003JB002889.

[13] W.R. Keller, D.L. Anderson, R.W. Clayton, Difficulties in seismically imaging in the Iceland hotspot, Geophys. Res. Lett. 27 (2000) 3993-3996.

[14] I.T. Bjarnason, C.J. Wolfe, S.C. Solomon, G. Gudmundsson, Initial results from the ICEMELT experiment: Body-wave delay times and shear-wave splitting across Iceland, Geophys. Res. Lett. 23 (1996) 459-462.

[15] R.M. Allen et al., The thin hot plume beneath Iceland, Geophys. J. Int. 137 (1999) 51-63.

[16] D.W. Forsyth, A. Li, Array-analysis of two-dimensional variations in surface wave velocity and azimuthal anisotropy in the presence of multipathing interference, in: A. Levander, G. Nolet (Ed.), Seismic Earth: Array Analysis of Broadband Seismograms,, Geophys. Monogr. Ser., Vol. 157, AGU, Washington, D.C., 2005, pp81-97.

[17] A. Li, D.W. Forsyth, K.M. Fischer, Shear velocity structure and azimuthal anisotropy beneath eastern North America from Rayleigh wave inversion, J. Geophys. Res. 108 B8 (2003) doi:10.1029/2002JB002259.

[18] C.J. Thomson, Modeling surface waves in anisotropic structures I. Theory, Phys. 
Earth Planet. Int. 103 (1997) 195-206.

[19] B.L.N. Kennett, E.R. Engdahl, R. Buland, Constraints on seismic velocities in the earth from travel times, Geophys. J. Int. 122 (1995) 108-124.

[20] C.E. Nishimura, D.W. Forsyth, Rayleigh wave phase velocities in the Pacific with implications for azimuthal anisotropy and lateral heterogeneities, Geophys. J. 94 (1988) 479-501.

[21] J.B. Gaherty, Seismic evidence for hotspot-induced buoyant flow beneath the Reykjanes Ridge, Science 293 (2001) 1645-1647.

[22] Z. Du, G.R. Foulger, Variation in the crustal structure across central Iceland, Geophys. J. Int. 145 (2000) 246-264.

[23] W. Menke, V. Levin, Cold crust in a hot spot, Geophys. Res. Lett. 21 (1994) 19671970.

[24] W. Menke, V. Levin, R. Sethi, Seismic attenuation in the crust at the mid-Atlantic plate boundary in southwest Iceland, Geophys. J. Int. 122 (1995) 175-182.

[25] D.L. Anderson, T. Tanimoto, Y.S. Zhang, Plate tectonics and hotspots: the third dimension, Science 256 (1992) 1645-1651.

[26] J. Minder, R. F. Viso, C. R. Kincaid, Laboratory experiments on the interaction between on-axis plumes and segmented ridges, EOS Trans, AGU, 84(46), Fall Meet. Suppl., 2003, Abstract T41C-0238.

[27] H.C. Nataf, Y. Ricard, 3SMAC: An a priori tomographic model of the upper mantle based on geophysical modeling, Phys. Earth Planet. Int. 95(1996) 101-102.

[28] D.W. Forsyth, Geophysical constraints on mantle flow and melt generation beneath M mid-ocean ridges, in: J. Phipps Morgan, D.K. Blackman, and J. Sinton (Ed.) 
Mantle Flow and Melt Generation at Mid-Ocean Ridges, Geophys. Monogr. Ser., Vol. 71, AGU, Washington, D. C., 1992, pp 1-65.

[29] G. Ito, J. Line, C.W. Gable, Dynamics of mantle flow and melting at a ridgecentered hotspot: Iceland and the Mid-Atlantic Ridge, Earth Planet. Sci. Lett. 144 (1996) 53-74.

[30] G. Ito, Y. Shen, G. Hirth, C.J. Wolfe, Mantle flow, melting, and dehydration of the Iceland mantle plume, Earth Planet. Sci. Lett. 165 (1999) 81-96.

[31] G. Ito, Reykjanes ' $\mathrm{V}$ '-shaped ridges originating from a pulsing and dehydrating mantle plume, Nature 411 (2001) 681-684.

[32] T.H. Jordan, Mineralogies, densities, and seismic velocities of garnet lherzolites and their geophysical implications, in: F.R. Boyd, H.O.A. Meyer [Ed.] The Mantle Sample: Inclusions in Kimberlites and Other Volcanics, Vol.2, AGU, Washington, D.C., 1979, pp.1-14.

[33] J. Phipps Morgan, W.J., Morgan, E. Price, Hotspot melting generates both hotspot volcanism and a hotspot swell, J. Geophys. Res. 100 (1995) 8045-8062.

[34] C.T. Lee, Compositional variation of density and seismic velocities in natural peridotites at STP conditions: implications for seismic imaging of compositional heterogeneities in the upper mantle, J. Geophys. Res. 108 B9 (2003) doi:10.1029/2003JB002413.

[35] Y. Shen, D. W. Forsyth, Geochemical constraints on initial and final depths of melting beneath mid-ocean ridges, J. Geophys. Res. 100 (1995) 2211-2237.

[36] J.-G. Schilling, Iceland mantle plume: geochemical evidence along Reykjanes ridge, Nature 242 (1973) 565-571. 
[37] P.S. Meyer, H. Sigurdsson, J.G. Schilling, Petrological and geochemical variations along Iceland's neovolcanic zones, J. Geophys. Res. 90 (1985) 10,043-10,072.

[38] M.J. Cordery, G.F. Davies, I.H. Campbell, Genesis of flood basalts from eclogitebearing mantle plumes, J. Geophys. Res. 102 (1997) 20,179-20,197.

[39] G.R. Foulger, Plumes, or plate tectonic processes?, Astron. Geophys. 43 (2002) 6.19-6.23.

[40] M. Albers, U.R. Christensen, Channeling of plume flow beneath mid-ocean ridges, Earth Planet. Sci. Lett. 187 (2001) 207-220.

[41] I.T. Bjarnason, P.G. Silver, G. Rumpker, S.C. Solomon, Shear wave splitting across the Iceland hot spot: Results from the ICEMELT experiment, J. Geophys. Res., 107 (B12) (2002) doi:10.1029/2001JB000916.

[42] S. Pilidou, K. Priestley, O. Gudmundsson, E. Debayle, Upper mantle S-wave speed heterogeneity and anisotropy beneath the North Atlantic from regional surface wave tomography: the Iceland and Azores plumes, Geophys. J. Int. 159 (2004) 1057-1076. 


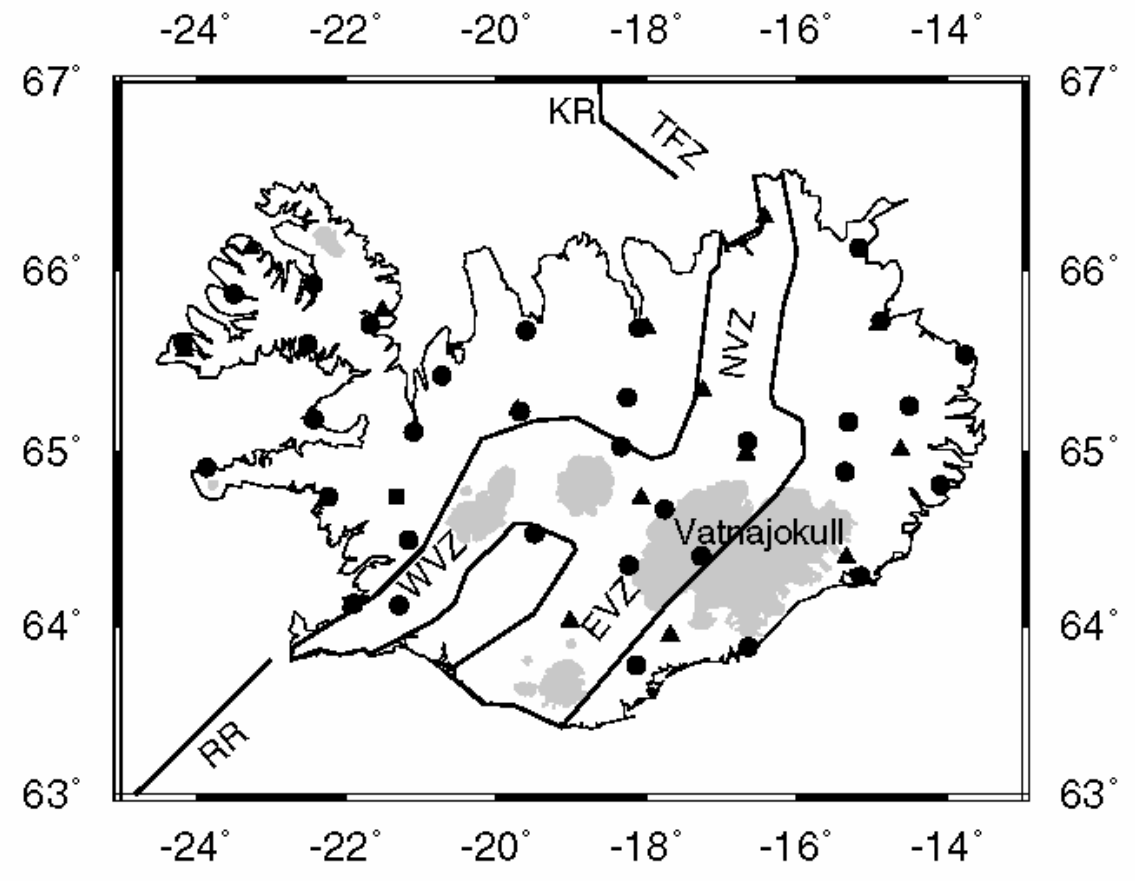

Fig. 1. Map of seismic stations and tectonics in Iceland. Circles are for the HOTSPOT stations and triangles for the ICEMELT stations. The square is a GSN station, BORG. Black lines outline the rift zones in Iceland and ridge segments in the Atlantic. Shaded areas mark the locations of major icecaps. The Iceland hotspot is located beneath the Vatnajokull icecap. WVZ, EVZ, and NVZ: Western, Eastern, and Northern Volcanic Zones; RR: Reykjanes Ridge; KR: Kolbeinsey Ridge; TFZ: Tjornes Fracture Zone. 


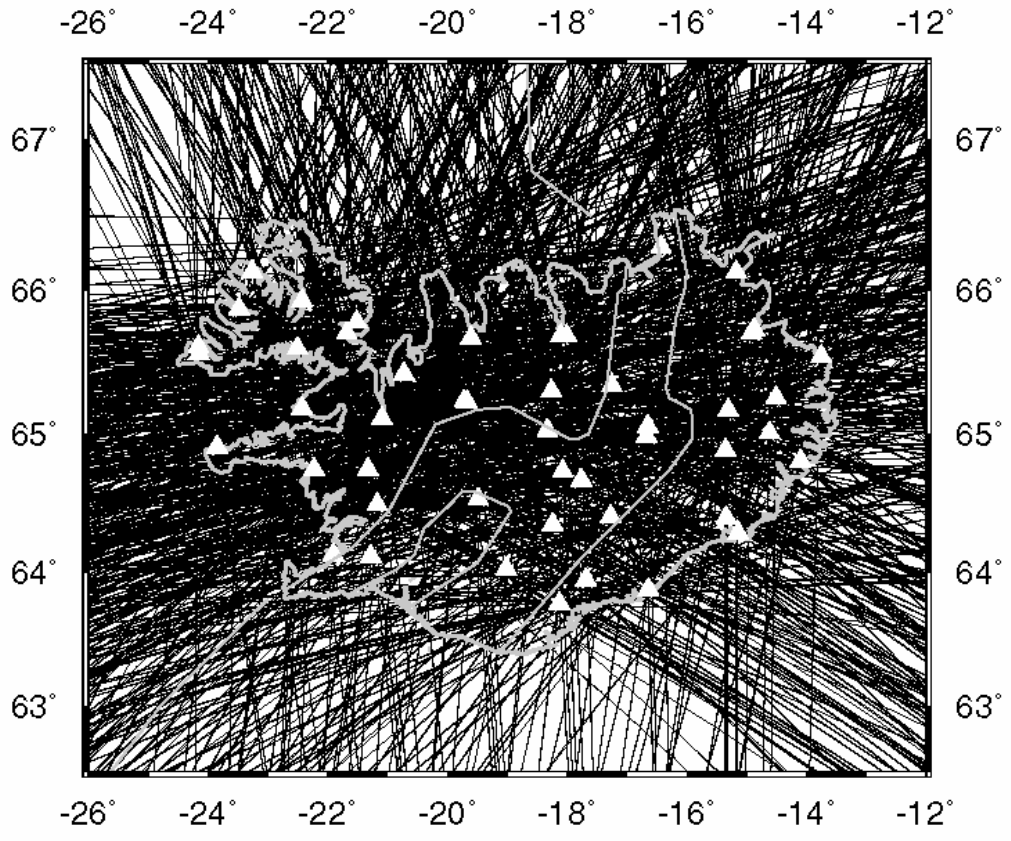

Fig. 2 Great circle ray paths to the ICEMELT and HOTSPOT stations (triangles) from 80 distant earthquakes. Gray lines outline the rift zones in Iceland and mid-ocean ridges in the North Atlantic. 


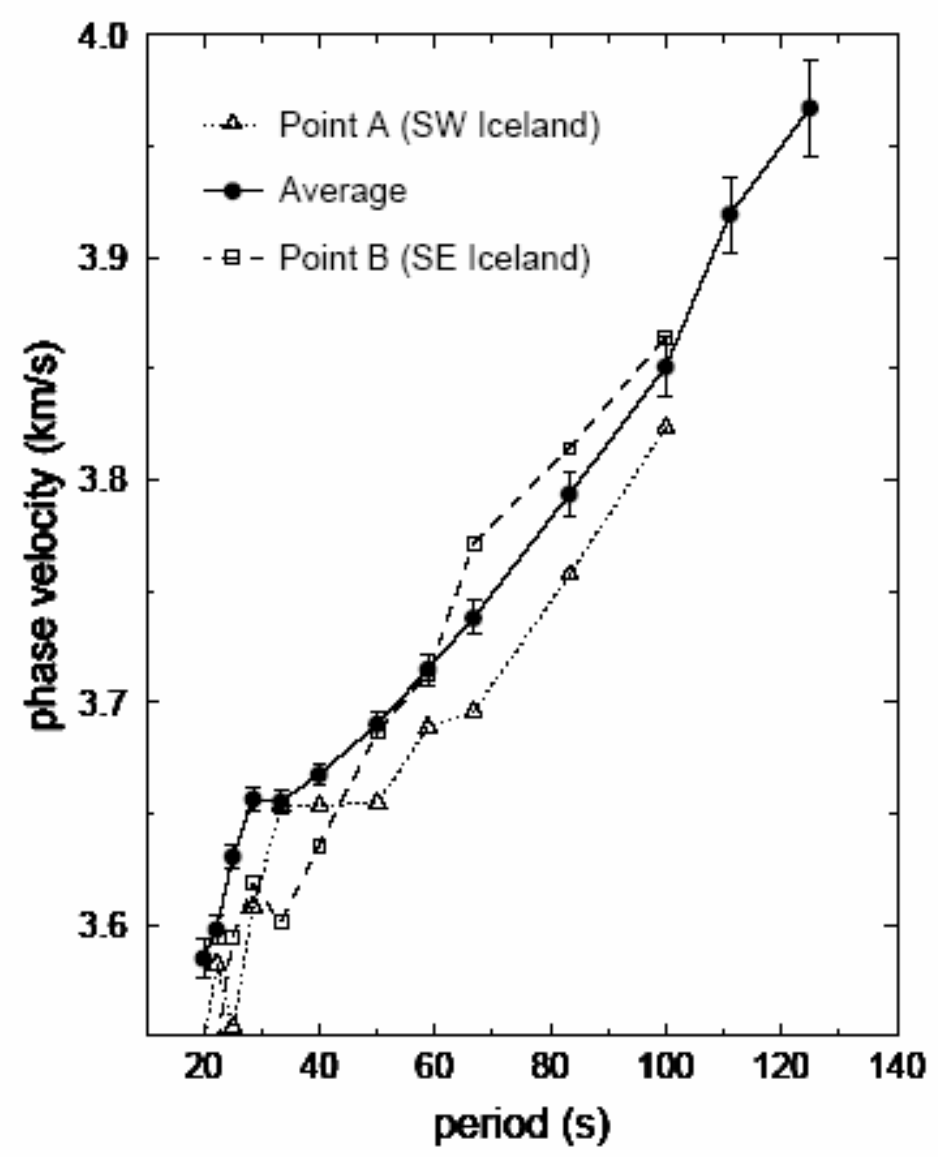

Fig. 3. Rayleigh wave phase velocities beneath Iceland. Black circles are average phase velocities in Iceland. Error bars represent twice standard deviations of phase velocities. Open triangles and squares are phase velocities for point $\mathrm{A}$ in southwestern Iceland and point B in southeastern Iceland, respectively. The locations of point A and point B are shown in Fig. 4f. 

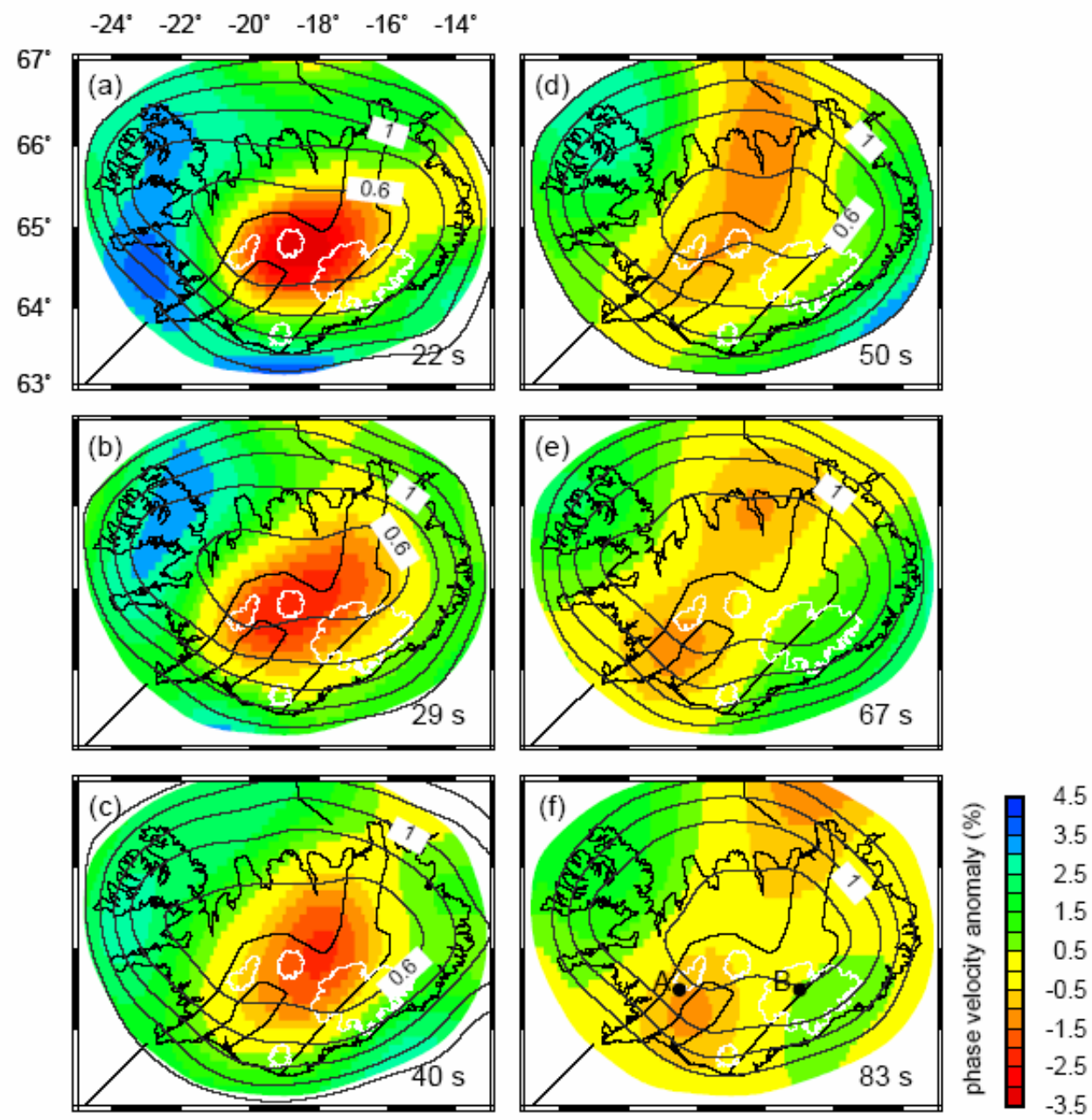

Fig. 4. Maps of Rayleigh wave phase velocity perturbations in Iceland at six periods. The perturbations are relative to the average phase velocities shown in Fig. 3. A smoothing length of $80 \mathrm{~km}$ was used in generating these maps. The dark gray contours are twice standard deviations of phase velocity perturbation at map points. All maps here after are clipped with the deviation contour of $1.4 \%$ for phase velocity perturbations at 50 $\mathrm{s}(\mathrm{e})$. Black lines mark the rift zones in Iceland and white lines are for icecaps. 


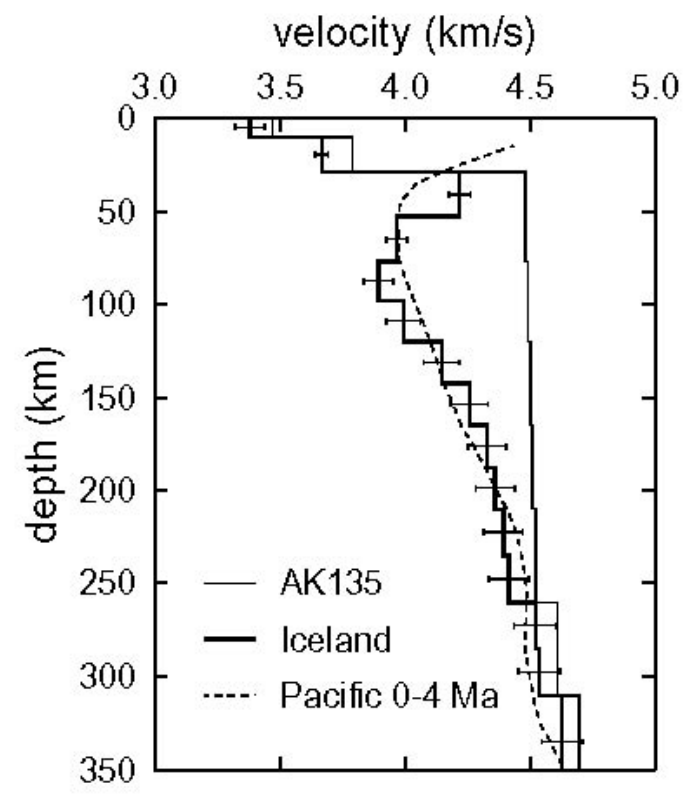

Fig. 5. 1-D Shear-wave velocity model of Iceland (thick line). It is obtained by inverting Rayleigh wave phase velocities averaged over Iceland at periods of $20 \mathrm{~s}$ to $125 \mathrm{~s}$ (Fig. 3). The thin line represents the AK135 model [19]. A model of Pacific at 0-4 Ma (dash line) [20] is plotted for comparison. 


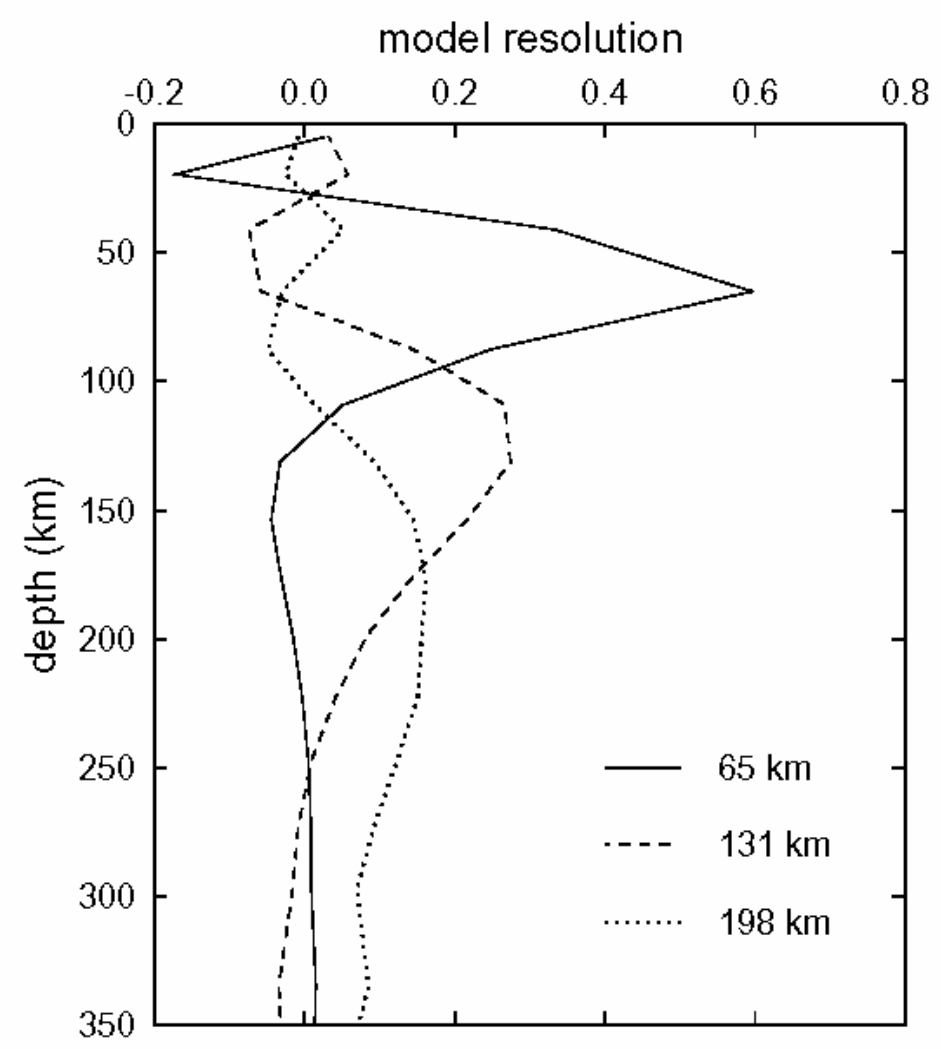

Fig. 6. Model resolution kernels corresponding to three layers at depths of $65 \mathrm{~km}, 131$ $\mathrm{km}$, and $198 \mathrm{~km}$, respectively. The large amplitude and narrow peak at $65 \mathrm{~km}$ indicates high resolution at this depth. The resolution decreases with depth. 

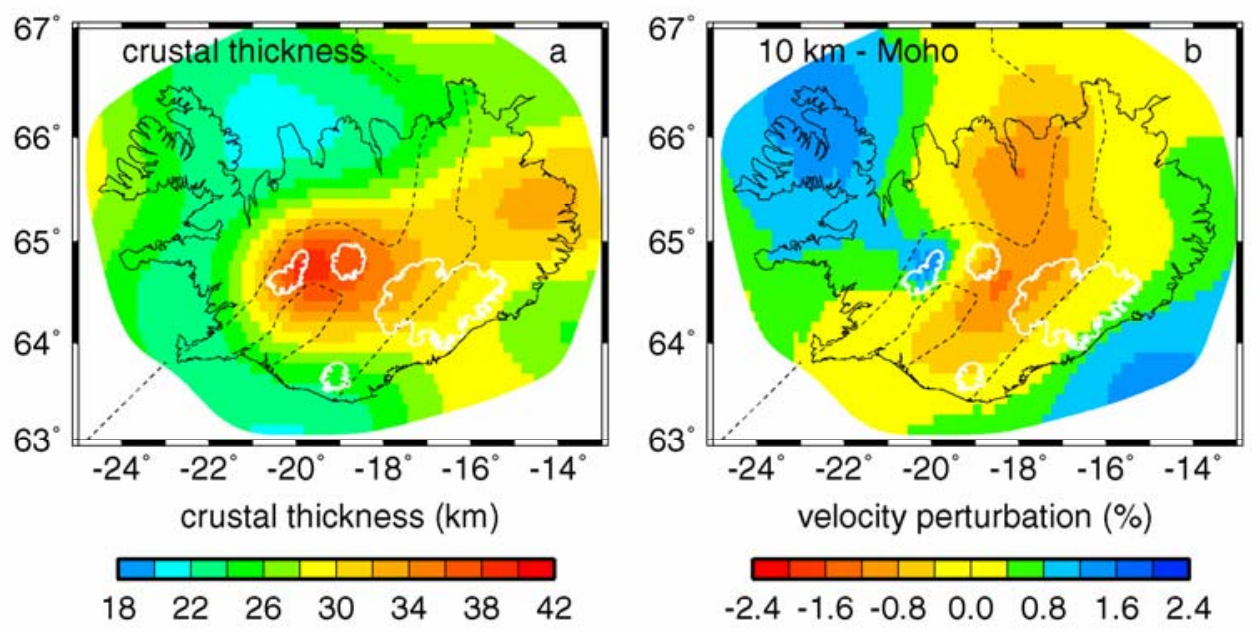

Fig. 7. Crustal thickness (a) and shear-wave velocity anomalies (b) in Iceland. Velocity anomalies in the lower crust are calculated relative to $3.67 \mathrm{~km} / \mathrm{s}$ in the $1-\mathrm{D}$ model of Iceland (Fig. 5). Dashed lines indicate location of the Mid-Atlantic Ridge near and on Iceland. White curves mark the icecaps. 


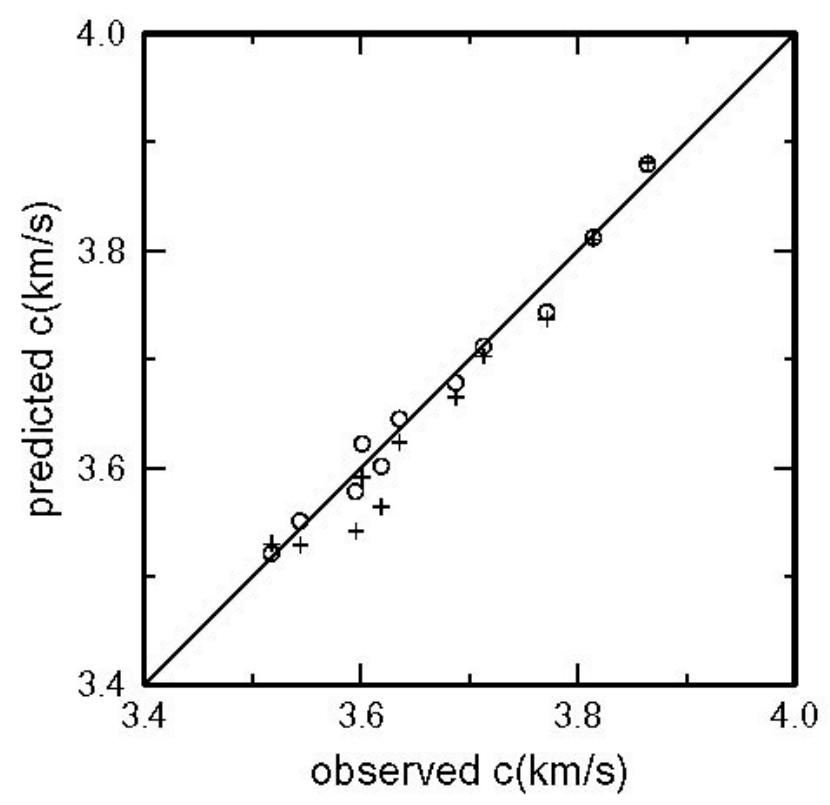

Fig. 8. Correlation between the observed and predicted phase velocities at the map point $\left(-17^{\circ}, 64.5^{\circ}\right)$ at the Iceland hotspot. Circles represent correlations for a model with a crustal thickness of $31 \mathrm{~km}$ and crosses for a model with a $45 \mathrm{~km}$ thick crust. 

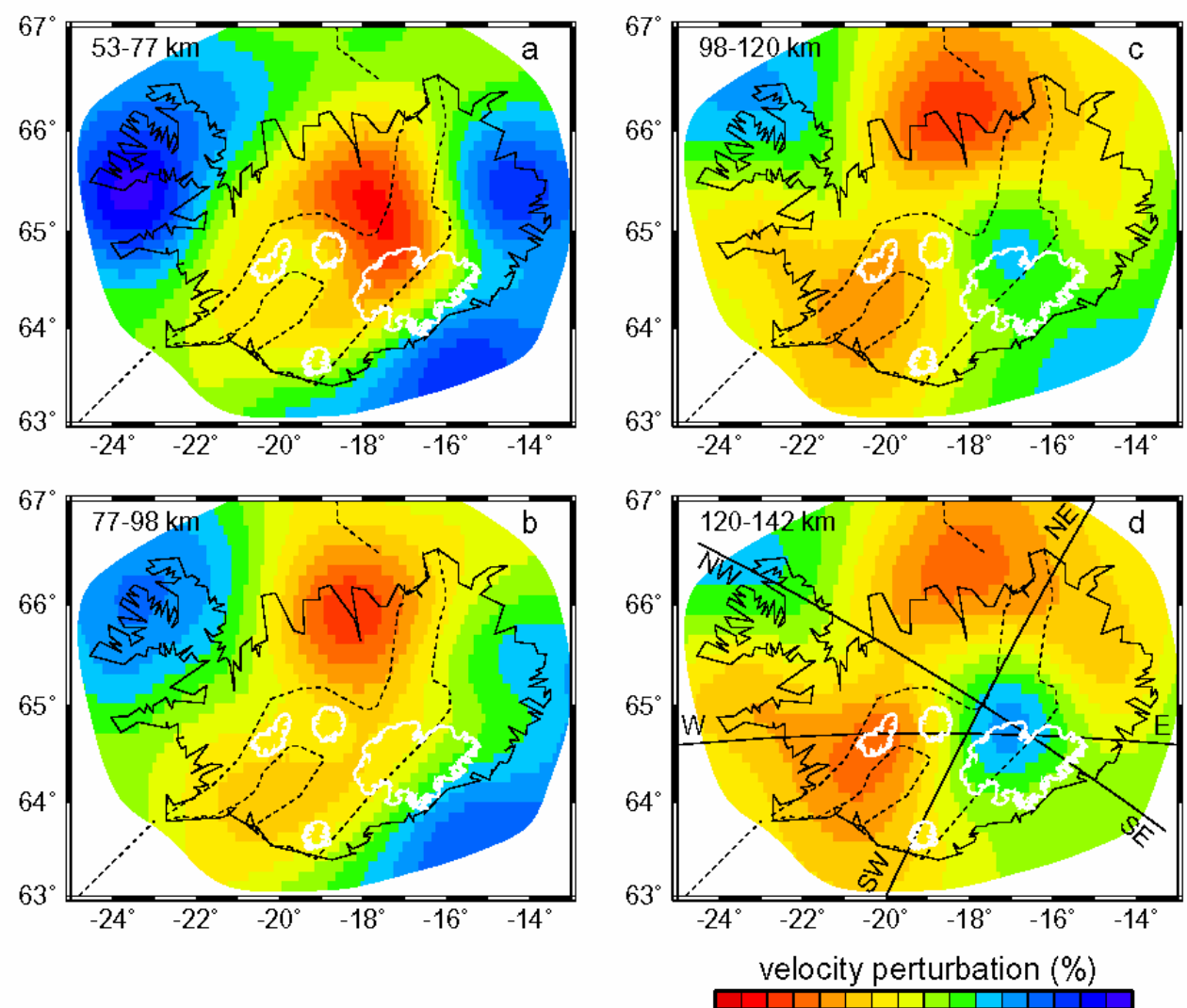

$-3.5-2.5-1.5-0.5 \quad 0.5 \quad 1.5 \quad 2.5 \quad 3.5 \quad 4.5$

Fig. 9. Maps of shear-wave velocity anomalies at four layers in the mantle beneath Iceland. The velocity anomalies are calculated relative to the 1-D model of Iceland (Fig. 5). Three black lines in (d) indicate the locations of three profiles in W-E, NW-SE, and SW-NE directions shown in Fig. 10. 

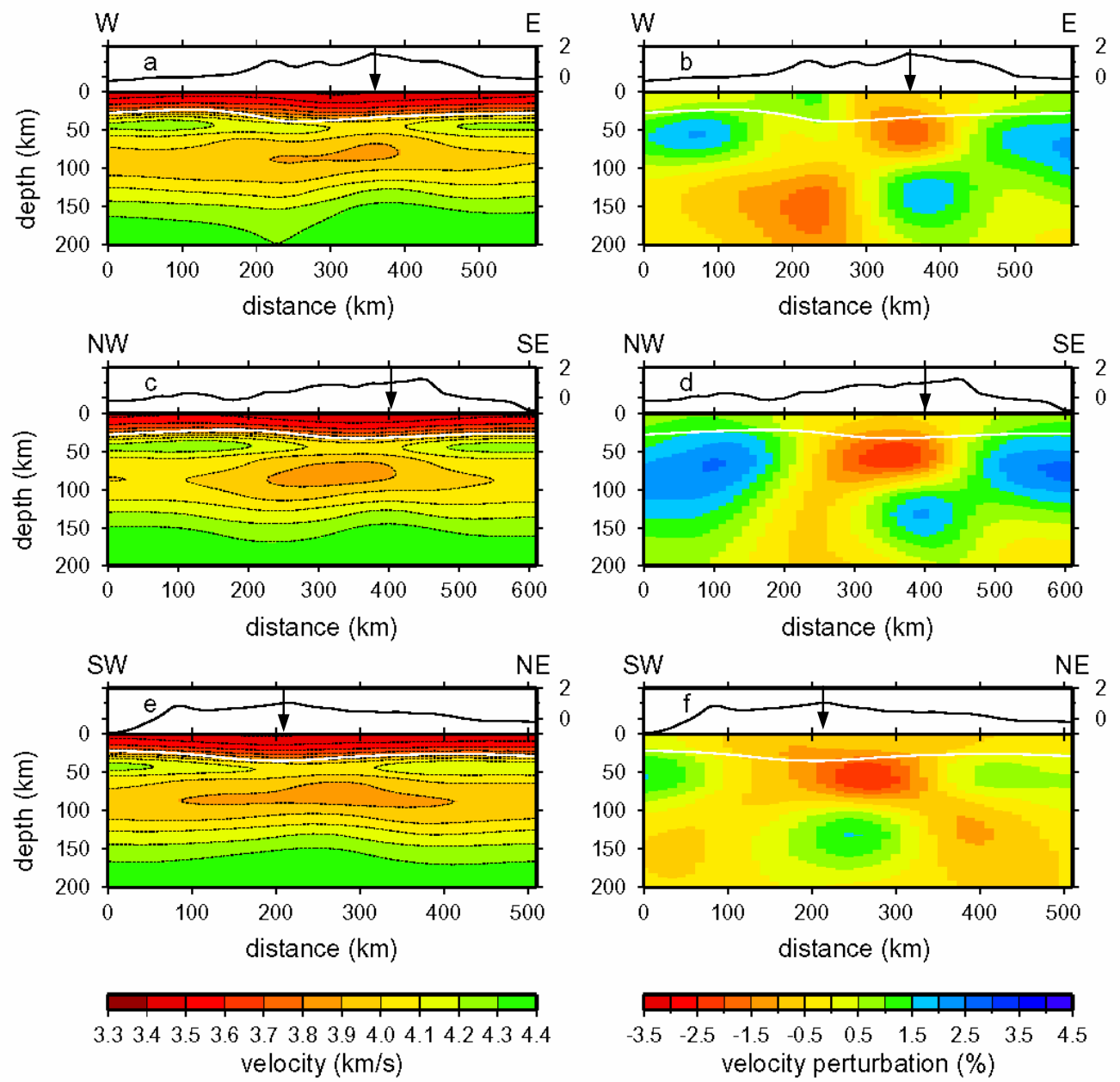

Fig. 10. Shear-wave velocity (a c, and e) and velocity perturbations (b, d, and f) along three profiles in W-E (a and b), NW-SE (c and d), and SW-NE (e and f) directions. The locations of the three profiles are shown in Fig. 9d. The elevation along each profile is plotted atop the velocity section as thick black lines. Dashed thin black lines in a, c, and e are velocity contours. White lines indicate the variation of Moho. Black arrows point to the location of the Iceland hotspot. 